\title{
Polyphasic approach for detecting toxigenic Fusarium species collected from imported grain and seed commodities
}

\section{Abd-Elsalam KA ${ }^{1,2^{*}}$, Amal-Asran $\mathrm{A}^{1,2}$, Alghuththaymi $\mathrm{MA}^{3}$, Khamis $\mathbf{Y}^{1}$, and Almoammar $\mathbf{H}^{4}$}

\author{
${ }^{1}$ Plant Pathology Research Institute, Agricultural Research Center (ARC), Giza, Egypt \\ ${ }^{2}$ Unit of Excellence in Nano-Molecular Plant Pathology Research (ARC), Giza, Egypt \\ ${ }^{3}$ Biology Department, Science and Humanities College, Alquwayiyah, Shaqra University, Saudi Arabia \\ ${ }^{4}$ King Abdulaziz City for Science and Technology (KACST), Saudi Arabia
}

Abd-Elsalam KA, Amal-Asran AM, Alghuththaymi MA, Khamis Y, Almoammar H - Polyphasic approach for detecting toxigenic Fusarium species collected from imported grain and seed commodities. Plant Pathology \& Quarantine 6(1), 81-99, Doi 10.5943/ppq/6/1/10

\begin{abstract}
The combined approach of bioassay, chemotype, PCR, and LAMP-PCR assays reported in this work allowed a rapid and accurate diagnostic of zearalenone, trichothecene and fumonisinproducing Fusarium species isolated from diverse regions. The most frequently isolated Fusarium species from grain and seed samples were $F$. graminearum $(12.36 \%)$, followed by $F$. solani $(10.3 \%), F$. avenaceum $(10.3 \%), F$. verticillioides $(8.24 \%), F$. heterosporum $(8.24 \%), F$. tricinctum (7.21\%) and $F$. fujikuroi $(5.15 \%)$. Fifty-seven percent of the isolates showed the ability to produce mycotoxins by using Nicotiana-based bioassay. Zearalenone (ZEA), trichothecene (TRI), and fumonisins (FUM) toxins were fabricated by tested isolates of $F$. graminearum, $F$. solani, $F$. culmorum, $F$. equiseti, $F$. semitectum, $F$. verticillioides, $F$. fujikuroi and $F$. poae. Tested isolates of $F$. acuminatum produced ZEA at levels ranging from $87-271 \mu \mathrm{g} /{ }^{\mathrm{g}-1}$. The production of fumonisins B1 from $F$. equiseti isolates was observed for the first time. Cluster analysis revealed the occurrence of six groups with similarities ranging from 85-98\%. The distribution of some Fusarium isolates within the phenogram was not in harmony with chemotype pattern. Three mycotoxin chemotypes were identified by chemical analysis and confirmed by PCR and LAMPPCR. PCR assays of Zea2, Tri6, and Fum B1 genes were used to forecast whether these isolates could produce ZEA, TRI and FUM, respectively. The presence of Tri5 gene was revealed in 33 of 103 examined isolates (34\%), which indicates the potential ability to produce trichothecene mycotoxins by these fungi, while 25 isolates possessed three of the analyzed genes. The greatest number of genes responsible for the production of three mycotoxins was examined in $F$. graminearum and $F$. equiseti while the smallest in $F$. avenaceum.
\end{abstract}

Key words - cereals - chemotype - Fusarium - LAMP-PCR - mycotoxins - PCR

\section{Introduction}

A broad range of Fusarium mycotoxins occur in cereals and other seeds. Mycotoxins, such as zearalenone (ZEA), deoxynivalenol (DON), and fumonisins (FUM) are the most frequent toxins 
produced by Fusarium spp. These toxin groups are considered the most risky to animal and human health (Stępień et al. 2014). Twenty-three Fusarium species were screened for fumonisin production and only $F$. verticillioides, $F$. proliferatum, and $F$. nygamai produce high levels of fumonisin (Huffman et al. 2010). F. graminearum, $F$. culmorum, $F$. sporotrichioides, and $F$. poae isolated from cereals are the main trichothecene producers (Wolny-Koładka et al. 2015). Gibberella fujikuroi complex, which includes both $F$. verticillioides and F. graminearum (Jeon et al. 2013), can contaminate cereals and many other foods with fumonisins and trichothecenes (Antonissen et al. 2014). Fast screening and detection of toxigenic fungi using biological methods including plants, yeasts, and bacteria were reviewed (Panigra 1993, Rivas-San Vicente et al. 2013). For instance, Arabidopsis thaliana was used as a model for observing mycobiota infection and mycotoxin production by Fusarium species (Urban et al. 2002). Similar uses of an A. thalianabased bioassay for exploring seed colonization by aflatoxigenic Aspergilli (Hammond et al 2007). Fusarium species can be identified morphologically, but differences between species are difficult to establish. Traditional toxigenic fungi classification and identification methods are based mainly on morphological characteristics and pathogenicity testing. These approaches require a fully equipped laboratory and usually are expensive, time-consuming and require considerable expertise in taxonomy and physiology of Fusarium species (Leslie \& Summerell 2006, Gong et al. 2014). To overcome these limitations the development of diagnostic tools for rapid, simple, and cost-effective detection of food-borne fungi is advantageous, especially on-site detection method (Ferrara et al. 2015). The current status and future of research direction is focused on use of multiple genes belonging to different clusters for the detection of toxigenic species. For instance, identify and quantify toxigenic Fusarium in cereals was achieved by use of markers targeting the trichodiene synthase encoding gene (tri5 and tri 6) gene in trichothecene-producing Fusarium. (Dawidziuk et al. 2014). The FUM cluster genes were used as a novel marker for classification and phylogenetic evaluation of the fumonisin-producing Fusarium species (Baird et al. 2008). Real-time PCR tests have been applied to detect food-borne pathogens. Nevertheless, the real time PCR assays need costly fluorescence detection systems (Law et al. 2014). LAMP-PCR was used for detecting fungal contamination in pepper and paprika powder (Zhang et al. 2014). LAMP tests have been developed for rapid detection of Phytophthora sojae (Dai et al. 2012), P. ramorum, F. oxysporum (Lu et al. 2015a), and some Fusarium specialized forms and races (Almasi \& Li 2013, Peng et al. 2013). Generally, LAMP-PCR was used to detect specific mycotoxin-producing fungi, such as Aspergillus carbonarius, A. niger and three species of Aspergillus section Flavi (Storari et al. 2013). Also, LAMP-PCR have been developed for the major FHB and toxigenic Fusarium in different plant materials (Niessen \& Vogel 2010, Abd-Elsalam 2011, Niessen 2012, Almoammar 2013, Lu et al. 2015b). Several authors have adopted successfully this criterion for selecting mycotoxin biosynthetic genes as LAMP target (Storari et al. 2013). Previous LAMP assays developed for toxigenic fungi were mainly targeted to housekeeping genes (Niessen \& Vogel 2010). A target gene involved directly in mycotoxin biosynthesis is preferred, as it is more closely-related to potential toxigenicity. The CYP51C gene species-specific DNA-based assay was used as a phylogenetic marker to identify Fusarium species (Wang et al. 2013). The optimized LAMP assay can be used to rapidly identify $F$. graminearum and $F$. equiseti with a lower limit of detection than conventional PCR amplification. The aims of the present research were (1) to describe the construction of a sensitive and inexpensive Nicotiana-based assay for fast screening of toxigenic fungi. It would be advantageous to be able to reproduce greenhouse symptoms in sensitive plant could first be confirmed; (2) to characterize and identify the main three toxins production by Fusarium isolates associated with cereal and seeds imported from different countries into Saudi Arabia and Egypt; (3) PCR assays of Zea2, Tri6, and Fum6 B1 genes were used to predict whether these isolates could produce zearalenone (ZEA), deoxynivalenol (DON), and fumonisins (FUM) respectively; and (4) to evaluate LAMP assay for detection of $F$. graminearum and $F$. equiseti based on the gaoA and CYP51C-genes, respectively,-and demonstrated that the assay is specific and efficient. 


\section{Materials \& Methods}

\section{Fusarium culture}

The study was performed using Fusarium species isolated from cereal and seeds collected from different countries and imported into Egypt and Saudi Arabia. In order to isolate the tested Fusarium, a total of 214 cereal samples were associated and examined. Fungi were isolated by surface-sterilizing 10 seeds per sample in $1 \%$ sodium hypochlorite solution in a $50 \mathrm{ml}$ beaker for 1 min and washed with three changes of sterile distilled water. Five seeds each were placed in Petri dishes with potato dextrose agar (PDA) media (Difco). Petri dishes were incubated for 7 days at $24^{\circ} \mathrm{C}$. Morphological identification of Fusarium spp. was approved according to Leslie \& Summerell (2006). The screened isolates were purified and monosporic cultures were maintained on PDA slants at $4^{\circ} \mathrm{C}$. The complete list of Fusarium isolates with relevant crops, and agroecological country is shown in Table 1.

\section{Intact in vivo bioassay}

The current biological assay is an alternative screening method to assess the phytotoxicity of Fusarium mycotoxins. Nicotiana seedlings were used to detect the biotoxicity of 103 isolates belonging to 25 Fusarium species. Fusarium isolates were inoculated on potato dextrose broth (PDB) and incubated for 3 weeks and conidiospores were harvested as previously reported by Hilton et al. (1999). Nicotiana benthamiana seedlings were inoculated by placing $10 \mu \mathrm{l}$ of conidial suspension (containing $10^{8}$ conidia) on each emerging seedling leaf. Three leaves per seedling were inoculated. Control plants were treated with $10 \mu \mathrm{l}$ of sterile distilled water. Inoculated plants were incubated in a moist chamber for $72 \mathrm{~h}$ and kept in a growth chamber at $21^{\circ} \mathrm{C}$ (day) $/ 18^{\circ} \mathrm{C}$ (night) temperatures with day/night regime of $16 \mathrm{~h} / 8 \mathrm{~h}$.

\section{Growth conditions for mycotoxin detection}

A total of 103 Fusarium isolates (73 from Saudi and 30 from Egypt) collocated from cereals originated from different geographical regions, were screened for their ability to produce three types of mycotoxins. Fusarium isolates were cultured in $250 \mathrm{~mL}$ Erlenmeyer flasks containing 50 $\mathrm{mL}$ of rice culture medium $(50 \mathrm{~g}$ of rice flour per $500 \mathrm{~mL}$ deionized water). The top of each flask was covered with aluminum foil, autoclaved and allowed to cool down in a hood for about $40 \mathrm{~min}$. Mycelia from PDA plates were gently scrapped from the agar, using sterile scalpels. Then, each flask was inoculated by adding the mycelia from the Fusarium isolates. The flasks were incubated in a regulated room at $24^{\circ} \mathrm{C}$ for about 28 days. Mycelia were harvested by filtration through Whatman no. 1 paper. The dry mycelium was ground to fine powder using a coffee blender with ethanol cleaning between samples. The ground samples were stored at $0^{\circ} \mathrm{C}$ until use.

\section{High-performance liquid chromatography}

High-performance liquid chromatography (HPLC) was used to detect the following mycotoxins: ZEA, TRI and FUM B1. Standards of these toxins were purchased from Sigma Chemical Company (St. Louis, MO, USA) and stored at $4^{\circ} \mathrm{C}$ in darkness. The procedure was performed as previously described in detail (Kushiro et al. 2015).

\section{DNA isolation}

The Fusarium isolates were inoculated onto PDA and incubated at $24^{\circ} \mathrm{C}$ for 7 days. Under sterilized laminar flow workstations, a piece of fresh mycelia and spores was scraped using sterile swabs and dipped in a $0.2 \mathrm{~mL}$ Eppendorf tube containing $100 \mu \mathrm{L} 10 \times$ (Tris and EDTA, pH 7.5). The tube was then heated at $95^{\circ} \mathrm{C}$ for $10 \mathrm{~min}$ in a thermblock (Eppendorf) and centrifuged at $3000 \mathrm{r}$ $\min ^{-1}$ for $1 \mathrm{~min}$. The isolated DNA was stored at $4^{\circ} \mathrm{C}$ in a refrigerator until used (Jia et al. 2014). 
Table 1 Fusarium isolates and their crops, agro-ecological country, their mycotoxins bioassay, chemotypes, conventional PCR, and LAMP-PCR specificity used in this study

\begin{tabular}{|c|c|c|c|c|c|c|c|c|c|c|c|c|}
\hline \multirow{2}{*}{ No. } & \multirow{2}{*}{ Fusarium species } & \multirow{2}{*}{ Crop } & \multirow{2}{*}{$\begin{array}{l}\text { Origin } \\
\text { country }\end{array}$} & \multirow{2}{*}{$\begin{array}{c}\text { Mycotoxins }^{1} \\
\text { Bioassay }\end{array}$} & \multicolumn{3}{|c|}{$\begin{array}{c}\text { Mycotoxins } \\
\mu \mathrm{g} / \mathrm{g}-1\end{array}$} & \multicolumn{3}{|c|}{ PCR } & \multicolumn{2}{|c|}{ LAMP-PCR } \\
\hline & & & & & ZEA & TRI & FUM-(B1) & ZEA2 & TRI6 & FUM6 & CYP51C & $\begin{array}{l}\text { gaoA } \\
\text { gene }\end{array}$ \\
\hline 20 & F. acuminatum & Wheat & Uzbekistan & - & 139 & 209 & ND & $\square$ & ! & $\square$ & $\square$ & $\square$ \\
\hline 26 & F. acuminatum & Wheat & France & घ & 74 & 87 & ND & $\square$ & घ & $\square$ & $\square$ & $\square$ \\
\hline 53 & F. acuminatum & Wheat & Uzbekistan & घ & 410 & 110 & ND & $\square$ & $\mathbf{\square}$ & $\square$ & $\square$ & $\square$ \\
\hline 69 & F. acuminatum & Wheat & Germany & घ & 246 & 271 & ND & $\square$ & घ & $\square$ & $\square$ & $\square$ \\
\hline 1 & F. annulatum & Barley & Sudan & $\square$ & ND & ND & ND & $\square$ & $\square$ & $\square$ & $\square$ & $\square$ \\
\hline 24 & F. annulatum & Sesame & Kenya & $\square$ & ND & ND & 1307 & $\square$ & $\square$ & घ & $\square$ & $\square$ \\
\hline 60 & F. annulatum & Sesame & Kenya & $\square$ & ND & ND & 1273 & $\square$ & $\square$ & घ & $\square$ & $\square$ \\
\hline 99 & F. annulatum & Sesame & Kenya & $\square$ & ND & ND & ND & $\square$ & $\square$ & $\square$ & $\square$ & $\square$ \\
\hline 72 & F. anthophilum & Wheat & Germany & $\square$ & ND & ND & ND & $\square$ & $\square$ & $\square$ & $\square$ & $\square$ \\
\hline 10 & F. avenaceum & Wheat & Canada & $\square$ & ND & ND & ND & $\square$ & $\square$ & $\square$ & $\square$ & $\square$ \\
\hline 12 & F. avenaceum & Wheat & USA & $\square$ & ND & ND & ND & $\square$ & $\square$ & $\square$ & $\square$ & $\square$ \\
\hline 29 & F. avenaceum & Wheat & USA & $\square$ & ND & ND & ND & $\square$ & $\square$ & $\square$ & $\square$ & $\square$ \\
\hline 44 & F. avenaceum & Wheat & Uzbekistan & $\square$ & ND & ND & ND & $\square$ & $\square$ & $\square$ & $\square$ & $\square$ \\
\hline 48 & F. avenaceum & Sorghum & USA & $\square$ & ND & ND & ND & $\square$ & $\square$ & $\square$ & $\square$ & $\square$ \\
\hline 50 & F. avenaceum & Sesame & Kenya & $\square$ & ND & ND & ND & $\square$ & $\square$ & $\square$ & $\square$ & $\square$ \\
\hline 67 & F. avenaceum & Wheat & Germany & $\square$ & ND & ND & ND & $\square$ & $\square$ & $\square$ & $\square$ & $\square$ \\
\hline 83 & F. avenaceum & Wheat & Uzbekistan & $\square$ & ND & ND & ND & $\square$ & $\square$ & $\square$ & $\square$ & $\square$ \\
\hline 87 & F. avenaceum & Sorghum & USA & $\square$ & ND & ND & ND & $\square$ & $\square$ & $\square$ & $\square$ & $\square$ \\
\hline 89 & F. avenaceum & Sesame & Kenya & $\square$ & ND & ND & ND & $\square$ & $\square$ & $\square$ & $\square$ & $\square$ \\
\hline 11 & F.brevicatenulatum & Sorghum & Nigeria & $\square$ & ND & ND & ND & $\square$ & $\square$ & $\square$ & $\square$ & $\square$ \\
\hline 3 & F. camptoceras & Barley & Kenya & $\square$ & ND & ND & ND & $\square$ & $\square$ & $\square$ & $\square$ & $\square$ \\
\hline 27 & F.chlamydosporum & Wheat & France & $\square$ & ND & 97 & ND & $\square$ & घ & $\square$ & $\square$ & $\square$ \\
\hline 42 & F.chlamydosporum & Soy & Canada & $\square$ & ND & 213 & ND & $\square$ & घ & $\square$ & $\square$ & $\square$ \\
\hline 103 & F.chlamydosporum & Soy & Canada & $\square$ & ND & 86 & ND & $\square$ & घ & $\square$ & $\square$ & $\square$ \\
\hline 13 & F. ciliatum & Yellow corn & Canada & $\square$ & ND & ND & ND & $\square$ & $\square$ & $\square$ & $\square$ & $\square$ \\
\hline 2 & F. culmorum & Corn & USA & - & 411 & 212 & 1366 & घ & घ & - & $\square$ & $\square$ \\
\hline 25 & F. culmorum & Wheat & France & a & 96 & 73 & 1147 & घ & घ & घ & $\square$ & $\square$ \\
\hline 73 & F. culmorum & Wheat & Germany & a & 175 & 130 & 1261 & घ & घ & घ & $\square$ & a \\
\hline 23 & F. decemcellulara & Barely & Sudan & $\square$ & ND & ND & ND & $\square$ & $\square$ & & $\square$ & $\square$ \\
\hline 22 & F. equiseti & Barley & Sudan & घ & 211 & 407 & 1.059 & घ & ! & घ & a & $\square$ \\
\hline 54 & F. equiseti & Corn & Argentina & - & 215 & 319 & ND & घ & घ & - & 口 & $\square$ \\
\hline
\end{tabular}


Table 1 Continue

\begin{tabular}{|c|c|c|c|c|c|c|c|c|c|c|c|c|}
\hline \multirow{2}{*}{ No. } & \multirow{2}{*}{ Fusarium species } & \multirow{2}{*}{ Crop } & \multirow{2}{*}{$\begin{array}{l}\text { Origin } \\
\text { country }\end{array}$} & \multirow{2}{*}{$\begin{array}{c}\text { Mycotoxins } \\
\text { Bioassay }\end{array}$} & \multicolumn{3}{|c|}{$\begin{array}{c}\text { Mycotoxins } \\
\mu \mathrm{g} / \mathrm{g}-1\end{array}$} & \multicolumn{3}{|c|}{ PCR } & \multicolumn{2}{|c|}{ LAMP-PCR } \\
\hline & & & & & ZEA & TRI & FUM-(B1) & ZEA2 & TRI6 & FUM6 & CYP51C & $\begin{array}{l}\text { gaoA } \\
\text { gene }\end{array}$ \\
\hline 93 & F. equiseti & Corn & Argentina & $\square$ & 80 & 244 & 0.879 & " & 口 & घ & घ & $\square$ \\
\hline 17 & F. flocciferum & Wheat & Germany & $\square$ & ND & ND & ND & $\square$ & $\square$ & $\square$ & $\square$ & $\square$ \\
\hline 56 & $F$. flocciferum & Wheat & France & $\square$ & ND & ND & ND & $\square$ & $\square$ & $\square$ & $\square$ & $\square$ \\
\hline 95 & $F$. flocciferum & Wheat & France & $\square$ & ND & ND & ND & $\square$ & $\square$ & $\square$ & $\square$ & $\square$ \\
\hline 14 & $F$. fujikuroi & Wheat & Germany & $\mathbf{\square}$ & ND & ND & 1083 & घ & $\square$ & $\mathbf{\square}$ & $\square$ & $\square$ \\
\hline 30 & F. fujikuroi & Wheat & Australia & घ & ND & ND & 1374 & घ & $\square$ & घ & $\square$ & $\square$ \\
\hline 40 & F. fujikuroi & Wheat & Uzbekistan & घ & ND & ND & 1759 & घ & $\square$ & घ & $\square$ & $\square$ \\
\hline 80 & F. fujikuroi & Wheat & Uzbekistan & घ & ND & ND & 987 & घ & $\square$ & घ & $\square$ & $\square$ \\
\hline 6 & $F$. graminearum & wheat & Uzbekistan & घ & 241 & 615 & 2020 & घ & $\square$ & घ & $\square$ & $\square$ \\
\hline 7 & F. graminearum & Wheat & Uzbekistan & घ & 117 & 421 & 1820 & घ & $\square$ & घ & $\square$ & घ \\
\hline 15 & $F$. graminearum & Wheat & Germany & घ & 321 & 752 & 2110 & घ & $\square$ & घ & $\square$ & घ \\
\hline 16 & $F$. graminearum & Wheat & Germany & घ & 247 & 493 & 1287 & $\square$ & घ & घ & $\square$ & घ \\
\hline 34 & $F$. graminearum & Barley & Sudan & घ & 511 & 276 & 1007 & घ & घ & घ & $\square$ & घ \\
\hline 39 & $F$. graminearum & Barley & Australia & घ & 371 & 813 & 1243 & घ & घ & घ & $\square$ & घ \\
\hline 41 & $F$. graminearum & Barley & Sudan & घ & 112 & 147 & 1055 & घ & घ & घ & $\square$ & घ \\
\hline 55 & $F$. graminearum & Wheat & Uzbekistan & घ & 180 & 591 & 1620 & घ & $\square$ & घ & $\square$ & $\square$ \\
\hline 71 & F. graminearum & Wheat & Germany & घ & 480 & 746 & 1370 & घ & $\square$ & घ & $\square$ & घ \\
\hline 78 & $F$. graminearum & Barley & Australia & घ & 197 & 837 & 1711 & घ & $\square$ & घ & $\square$ & घ \\
\hline 79 & F. graminearum & Barley & Sudan & घ & 396 & 134 & 873 & घ & घ & घ & $\square$ & घ \\
\hline 94 & $F$. graminearum & Wheat & Uzbekistan & घ & 273 & 219 & 1110 & घ & घ & घ & $\square$ & घ \\
\hline 35 & F. heterosporium & Wheat & Uzbekistan & घ & 147 & ND & ND & घ & $\square$ & $\square$ & $\square$ & $\square$ \\
\hline 63 & F. heterosporium & Wheat & France & घ & 233 & ND & ND & घ & $\square$ & $\square$ & $\square$ & $\square$ \\
\hline 92 & $F$. heterosporium & Wheat & France & घ & 176 & ND & ND & घ & $\square$ & $\square$ & $\square$ & $\square$ \\
\hline 58 & F. heterosporum & Sesame & Sudan & घ & 420 & ND & ND & घ & $\square$ & $\square$ & $\square$ & $\square$ \\
\hline 64 & $F$. heterosporum & Wheat & USA & घ & 109 & ND & ND & घ & $\square$ & $\square$ & $\square$ & $\square$ \\
\hline 81 & F. heterosporum & Wheat & USA & घ & 359 & ND & ND & घ & $\square$ & $\square$ & $\square$ & $\square$ \\
\hline 97 & F. heterosporum & Sesame & Sudan & $\square$ & 633 & ND & ND & घ & $\square$ & $\square$ & $\square$ & $\square$ \\
\hline 102 & F. heterosporum & Wheat & Uzbekistan & घ & 254 & ND & ND & घ & $\square$ & $\square$ & $\square$ & $\square$ \\
\hline 66 & F. moniliforme & Wheat & Germany & $\square$ & ND & ND & 1413 & $\square$ & $\square$ & घ & $\square$ & $\square$ \\
\hline 4 & F. oxysporum & Wheat & Australia & $\square$ & ND & ND & ND & - & $\square$ & $\square$ & $\square$ & $\square$ \\
\hline 68 & $\begin{array}{l}\text { F. oxysporum f. sp. } \\
\text { acuformis }\end{array}$ & Wheat & Germany & $\square$ & ND & ND & ND & $\square$ & $\square$ & $\square$ & $\square$ & $\square$ \\
\hline 21 & $F$. poae & Soy & USA & $\square$ & ND & ND & 897 & $\square$ & $\square$ & 口 & $\square$ & $\square$ \\
\hline
\end{tabular}


Table 1 Continue

\begin{tabular}{|c|c|c|c|c|c|c|c|c|c|c|c|c|}
\hline \multirow{2}{*}{ No. } & \multirow{2}{*}{ Fusarium species } & \multirow{2}{*}{ Crop } & \multirow{2}{*}{$\begin{array}{l}\text { Origin } \\
\text { country }\end{array}$} & \multirow{2}{*}{$\begin{array}{c}\text { Mycotoxins } \\
\text { Bioassay }\end{array}$} & \multicolumn{3}{|c|}{$\begin{array}{c}\text { Mycotoxins } \\
\mu \mathrm{g} / \mathrm{g}-1\end{array}$} & \multicolumn{3}{|c|}{ PCR } & \multicolumn{2}{|c|}{ LAMP-PCR } \\
\hline & & & & & ZEA & TRI & FUM-(B1) & ZEA2 & TRI6 & FUM6 & CYP51C & $\begin{array}{c}\text { gaoA } \\
\text { gene }\end{array}$ \\
\hline 28 & F.poae & Soy & Canada & $\square$ & ND & ND & 1000 & $\square$ & $\square$ & a & $\square$ & $\square$ \\
\hline 46 & $F$. poae & Alfa alfa & Canada & $\square$ & ND & ND & 664 & $\square$ & $\square$ & घ & $\square$ & $\square$ \\
\hline 85 & $F$. poae & Alfa alfa & Canada & $\square$ & ND & ND & 478 & $\square$ & $\square$ & $\bar{\square}$ & $\square$ & $\square$ \\
\hline 37 & F. proliferatum & Corn & USA & $\square$ & 757 & ND & 1400 & $\square$ & $\square$ & घ & $\square$ & $\square$ \\
\hline 62 & F. proliferatum & Wheat & Germany & $\square$ & 430 & ND & 1211 & $\square$ & $\square$ & घ & $\square$ & $\square$ \\
\hline 76 & F. proliferatum & Corn & USA & घ & 819 & ND & 1545 & $\square$ & $\square$ & घ & $\square$ & $\square$ \\
\hline 101 & F. proliferatum & Wheat & Germany & घ & 744 & ND & 1133 & घ & $\square$ & घ & $\square$ & $\square$ \\
\hline 38 & F. semitectum & Corn & Kenya & $\square$ & 211 & 224 & 776 & 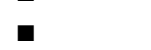 & - & $\bar{\square}$ & $\square$ & $\square$ \\
\hline 77 & F. semitectum & Corn & Kenya & $\square$ & ND & 612 & 1120 & घ & घ & घ & $\square$ & $\square$ \\
\hline 9 & $F$. solani & Soy bean & USA & घ & 346 & 840 & 723 & . & $\overline{-}$ & $\square$ & $\square$ & $\square$ \\
\hline 18 & F. solani & Corn & Nigeria & घ & 109 & 259 & 912 & घ & - & घ & $\square$ & $\square$ \\
\hline 32 & F. solani & Yellow corn & Kenya & घ & 148 & 476 & 1140 & घ & 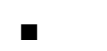 & घ & $\square$ & $\square$ \\
\hline 45 & F. solani & Soy & USA & घ & 228 & 921 & 1207 & घ & घ & घ & $\square$ & $\square$ \\
\hline 51 & F. solani & Sesame & Kenya & घ & 613 & 248 & 934 & घ & घ & घ & $\square$ & $\square$ \\
\hline 57 & F. solani & Soy & USA & घ & 412 & 647 & 488 & घ & घ & घ & $\square$ & $\square$ \\
\hline 65 & F. solani & Wheat & Germany & घ & 387 & 233 & 1270 & घ & घ & घ & $\square$ & $\square$ \\
\hline 84 & $F$. solani & Soy & USA & 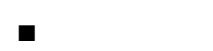 & 571 & 476 & 1149 & $\square$ & $\bar{\square}$ & $\square$ & $\square$ & $\square$ \\
\hline 90 & F. solani & Sesame & Kenya & घ & 446 & 623 & 793 & घ & - & घ & $\square$ & $\square$ \\
\hline 96 & F. solani & Soy & USA & घ & 246 & 197 & 918 & घ & $\overline{-}$ & घ & $\square$ & $\square$ \\
\hline 33 & F. sporotrichioides & Yellow corn & Kenya & $\square$ & 455 & ND & ND & घ & $\square$ & $\square$ & $\square$ & $\square$ \\
\hline 52 & F. sporotrichioides & Sesame & Nigeria & $\square$ & ND & ND & ND & घ & $\square$ & $\square$ & $\square$ & $\square$ \\
\hline 91 & F. sporotrichioides & Sesame & Nigeria & $\square$ & 742 & ND & ND & $\square$ & $\square$ & $\square$ & $\square$ & $\square$ \\
\hline 70 & F. sportichoides & Wheat & Germany & $\square$ & ND & ND & ND & घ & $\square$ & $\square$ & $\square$ & $\square$ \\
\hline 5 & $F$. tricinctum & Wheat & Australia & घ & 742 & ND & ND & घ & $\square$ & $\square$ & $\square$ & $\square$ \\
\hline 31 & F. tricinctum & Wheat & Australia & घ & 389 & ND & ND & घ & $\square$ & $\square$ & $\square$ & $\square$ \\
\hline 43 & F. tricinctum & Wheat & Canada & घ & 912 & ND & ND & घ & $\square$ & $\square$ & $\square$ & $\square$ \\
\hline 59 & F. tricinctum & Barley & Sudan & घ & 734 & ND & ND & घ & $\square$ & $\square$ & $\square$ & $\square$ \\
\hline 74 & F. tricinctum & Wheat & Germany & घ & 841 & ND & ND & घ & $\square$ & $\square$ & $\square$ & $\square$ \\
\hline 82 & F. tricinctum & Wheat & Canada & 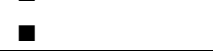 & 397 & ND & ND & घ & $\square$ & $\square$ & $\square$ & $\square$ \\
\hline
\end{tabular}


Table 1 Continue

\begin{tabular}{|c|c|c|c|c|c|c|c|c|c|c|c|c|}
\hline \multirow{2}{*}{ No. } & \multirow{2}{*}{ Fusarium species } & \multirow{2}{*}{ Crop } & \multirow{2}{*}{$\begin{array}{l}\text { Origin } \\
\text { country }\end{array}$} & \multirow{2}{*}{$\begin{array}{c}\text { Mycotoxins }^{1} \\
\text { Bioassay }\end{array}$} & \multicolumn{3}{|c|}{$\begin{array}{c}\text { Mycotoxins } \\
\mu \mathrm{g} / \mathrm{g}-1\end{array}$} & \multicolumn{3}{|c|}{ PCR } & \multicolumn{2}{|c|}{ LAMP-PCR } \\
\hline & & & & & ZEA & TRI & FUM-(B1) & ZEA2 & TRI6 & FUM6 & CYP51C & $\begin{array}{l}\text { gaoA } \\
\text { gene }\end{array}$ \\
\hline 98 & F. tricinctum & Barley & Sudan & घ & 501 & ND & ND & a & $\square$ & $\square$ & $\square$ & $\square$ \\
\hline 8 & F. verticillioides & Yellow corn & Canada & $\square$ & ND & ND & 873 & $\square$ & $\square$ & घ & $\square$ & $\square$ \\
\hline 19 & F. verticillioides & Wheat & Uzbekistan & $\square$ & ND & ND & 1394 & $\square$ & $\square$ & - & $\square$ & $\square$ \\
\hline 36 & F. verticillioides & Corn & Argentina & घ & ND & ND & 1190 & $\square$ & $\square$ & - & $\square$ & $\square$ \\
\hline 47 & F. verticillioides & Yellow corn & Nigeria & $\square$ & ND & ND & 1074 & $\square$ & $\square$ & - & $\square$ & $\square$ \\
\hline 61 & F. verticillioides & Wheat & France & $\square$ & ND & ND & 1100 & $\square$ & $\square$ & - & $\square$ & $\square$ \\
\hline 75 & F. verticillioides & Corn & Argentina & $\mathbf{\square}$ & ND & ND & 1234 & $\square$ & $\square$ & - & $\square$ & $\square$ \\
\hline 86 & F. verticillioides & Yellow corn & Nigeria & $\square$ & ND & ND & 615 & $\square$ & $\square$ & - & $\square$ & $\square$ \\
\hline 100 & F. verticillioides & Wheat & France & घ & ND & ND & 1220 & $\square$ & $\square$ & - & $\square$ & $\square$ \\
\hline 88 & Fusarium spp. & Wheat & Canada & $\square$ & ND & ND & ND & घ & $\square$ & $\square$ & $\square$ & $\square$ \\
\hline 49 & Fusarium spp.* & Wheat & Canada & $\square$ & ND & ND & ND & $\square$ & $\square$ & $\square$ & घ & $\square$ \\
\hline
\end{tabular}

Mycotoxins bioassay (sensitivity of Nicotiana seedlings to fungal filtration), Mycotoxins were determined by using HPLC.

This isolate was considered unknown. It did not have the ability to form any spores.

ND $=$ not detected. $\square$ negative results; $\square$ positive results. 


\section{PCR assay}

PCR amplifications were performed in volumes of $25 \mathrm{~mL}$ containing $50 \mathrm{ng}$ of fungal genomic DNA, $0.5 \mu \mathrm{L} 100 \mathrm{mmol} \mathrm{l}^{-1}$ of each primer, $12 \mu \mathrm{L}$ PCR buffer $\left(50 \mathrm{mmol} \mathrm{l}^{-1} \mathrm{KCl}, 1.5 \mathrm{mmol}\right.$ $\mathrm{l}^{-1} \mathrm{MgCl} 2,10 \mathrm{mmol}^{-1}$ Tris-HCl, $\mathrm{pH} 8.8,0.1 \%$ Triton X-100), $0.5 \mu \mathrm{L}$ Taq DNA Polymerase (Jena Bioscience), $2.5 \mu \mathrm{L}$ of dNTPs $(10 \mathrm{mM})$ and $7 \mu \mathrm{L}$ PCR water. PCR targeting zea2, tri6 and fum6 gene was performed as follows. After a $5 \mathrm{~min}$ denaturation at $94^{\circ} \mathrm{C}$, the $\mathrm{PCR}$ mixtures were subjected to 35 cycles of amplification at $94^{\circ} \mathrm{C}$ for $45 \mathrm{~s}, 53-56^{\circ} \mathrm{C}$ for $1 \mathrm{~min}$, and $72^{\circ} \mathrm{C}$ for $1 \mathrm{~min}$ with the final extension of $10 \mathrm{~min}$ at $72^{\circ} \mathrm{C}$. Amplification was performed by using Biometra TPersonal Thermal Cycler. PCR products were also analysed by gel electrophoresis $(5 \mu \mathrm{L}$ aliquots on 1.5\% agarose gel). The DNA molecular weight marker of DNA ladder DL 2000 (TaKaRa, Japan) was used to determine the size of the products. PCR primers used in current research are summarized in Table 2.

Table 2 Primers and their nucleotide sequences and product sizes used in PCR analysis (Dawidziuk et al. 2014).

\begin{tabular}{llcc}
\hline \multicolumn{1}{c}{ Primers name } & \multicolumn{1}{c}{ Sequence $\left(\mathbf{5}^{\prime} \mathbf{- 3}\right.$ ') } & $\begin{array}{c}\text { PCR } \\
\text { products } \\
\text { (base pairs) }\end{array}$ & Target \\
\hline ZEA2_dm_fA1 & ACM TCA CCA TCM AAR TTC TG & 340 & Zea2 \\
ZEA2_dm_rA1 & GCR TCY CKG TAR TCR CTC AT & & Zea2 \\
TRI6_dm_fA2 & TAT GAA TCA CCA ACW TTC GA & 526 & Tri 6 \\
TRI6_dm_rA1 & CGC CTR TAR TGA TCY CKC AT & & Tri 6 \\
FUM6_dm_fA2 & GTY TCR TGT CCK GCA ATG AG & 672 & Fum6 \\
FUM6_dm_rA1 & GGY TCK TTT GAG TGG TGG C & & Fum6 \\
\hline
\end{tabular}

Zearalenone polyketide synthase (zea2), Zinc finger transcription factor (tri6), Oxygenase (fum6)

\section{Loop-mediated isothermal amplification.}

The LAMP mixture in $25 \mathrm{~mL}$ total volume consisted of the following: 1 Thermo buffer (containing $2 \mathrm{mM} \mathrm{MgSO} 4$ ), $6 \mathrm{mM}$ of MgSO4, $0.8 \mathrm{M}$ of betaine (Sigma-Aldrich, St. Louis, MO), $1.4 \mathrm{mM}$ of dNTP, FIP and BIP (1.6 mM each), loop-F and loop-B (0.8 M each), F3 and B3 primers $(0.2 \mathrm{mM}$ each), Bst DNA polymerase (8 U) (New England BioLabs), dd $\mathrm{H} 2 \mathrm{O}$ and $2 \mathrm{~mL}$ of DNA template. The LAMP reaction was carried out at $63^{\circ} \mathrm{C}$ for 1 hour and terminated at $80^{\circ} \mathrm{C}$ for 2 minutes in a water bath. The template DNA was omitted in one reaction for negative control. LAMP amplicons were analyzed similarly by naked eye and electrophoresis (Abd-Elsalam et al. 2011). LAMP specificity was evaluated by performing the assay with 103 Fusarium DNA template extracted using by simplified protocols. Specificity tests were performed two times. LAMP primers are summarized in Table 3.

\section{Dendrogram analysis for mycotoxin profiles}

Dendrogram presents the accurate and defined analysis of the distance in the genetics of Fusarium species by groupings the strains based on their mycotoxin producing ability. Mycotoxins concentrations per isolate were analyzed using cluster analysis. SPSS 14 software package (www.spss.com) was used for cluster analysis by unweighted pair-group method based on arithmetic mean (UPGMA).

\section{Results}

\section{Morphological characterization}

The Fusarium species most frequently isolated from grain samples were $F$. graminearum $(12.36 \%)$, followed by $F$. solani $(10.3 \%), F$. avenaceum $(10.3 \%), F$. verticillioides $(8.24 \%), F$. heterosporum 
(8.24\%), F. tricinctum (7.21\%) and F. fujikuroi (5.15\%). In our survey, three species, $F$. graminearum, $F$. solani and $F$. avenaceum, contributed similarly to around a third of tested isolates. $F$. solani, $F$. avenaceum $(10.3 \%), F$. sportichoides and $F$. proliferatum, $F$. poae, $F$. annulatum, $F$. acuminatum $(4.12 \%)$ were obtained in equal frequency. $F$. flocciferum, $F$. equiseti, $F$. chlamydosporum, Fusarium spp., F. semitectum, F. oxysporum, F. culmorum, and F. moniliforme were found in lower percentages. Agro-ecological variations in Fusarium species composition were detected within our sampling (Table 1, Fig. 1).

Table 3 Primers used for loop-mediated isothermal amplification for $F$. graminearum and $F$. equiseti

LAMP- primers for $\boldsymbol{F}$. equiseti (Lu et al. 2015b)

\begin{tabular}{|c|c|c|c|}
\hline Primers name & Sequence $\left(5^{\prime}-3^{\prime}\right)$ & Length & Target \\
\hline F3 (forward outer) & GCGTACCCGGTACCGAAT & 18 & CYP51C \\
\hline $\begin{array}{l}\text { B3(backward } \\
\text { outer) }\end{array}$ & GGACTGGTGACAGACTTGTT & 20 & CYP51C \\
\hline $\begin{array}{l}\text { FIP (forward } \\
\text { inner) }(F 1 C+F 2)\end{array}$ & GGAGGGTCGAGGGAAGAACTCTTAGTGCCTCCGTCCCATAC & 41 & CYP51C \\
\hline $\begin{array}{l}\text { BIP (backward } \\
\text { inner) (B1C + B2) }\end{array}$ & TGGGATCCTCATCGCTGGGA-CCGAAGCCATAATCCACAGT & 40 & CYP51C \\
\hline LF (loop forward) & TGCCAGGAGATGCAAGAAGT & 20 & CYP51C \\
\hline $\begin{array}{l}\text { LB (loop } \\
\text { backward) }\end{array}$ & CGAGCCTCTTGAGAAGAACGCC & 22 & CYP51C \\
\hline \multicolumn{4}{|c|}{ LAMP- primers for $\boldsymbol{F}$. graminearum (Abd-Elsalam et al. 2011) } \\
\hline F3 (forward outer) & AGG GAG TCT TCA GTT CCT GA & 20 & gaoA gene \\
\hline $\begin{array}{l}\text { B3(backward } \\
\text { outer) }\end{array}$ & GTG AGG GGG CTT TGG ATC & 18 & gaoA gene \\
\hline $\begin{array}{l}\text { FIP (forward } \\
\text { inner) (F1C + F2) }\end{array}$ & CGCAAGTGACGGCCCAGTTGCTTCGAGCCTCAGCACCTA & 39 & gaoA gene \\
\hline $\begin{array}{l}\text { BIP (backward } \\
\text { inner) (B1C + B2) }\end{array}$ & TGCAACAAGGCCATTGATGGCCGTTGGCGCCATAGAATGT & 40 & gaoA gene \\
\hline LF (loop forward) & GTTGCGAGAAATGGCGCTTCC & 21 & gaoA gene \\
\hline $\begin{array}{l}\text { LB (loop } \\
\text { backward) }\end{array}$ & ACAAGGATACCTTTTGGCAC & 20 & gaoA gene \\
\hline
\end{tabular}

\section{Nicotiana-based bioassay for mycotoxin screening}

The filtration of liquid culture media was used to screen 103 Fusarium isolates for mycotoxin production. In the positive seedlings, young leaves were tiny and indistinct or chlorotic with asymmetrical margins, spotting or necrotic areas. Leaf tips may yellow and curl downhill. Leaf size was reduced and overall growth will be stunted (Fig. 2). Fifty-seven percent of the total isolates showed the ability to produce simultaneously mycotoxins by using Nicotiana-based bioassay (Table 1). 


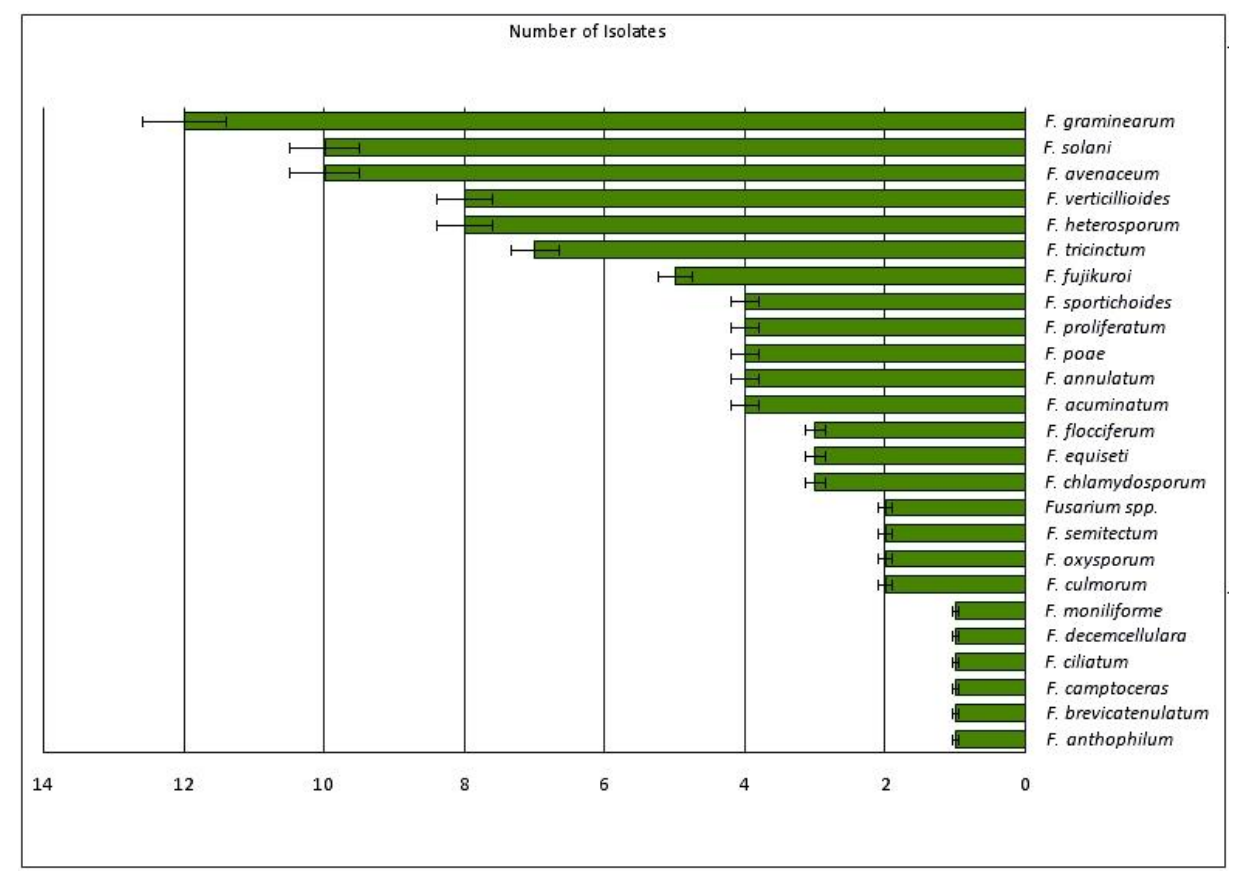

Fig 1 - Differences in relative frequency of isolation were observed among species. Overall, $F$. graminearum had the highest frequency of recovery followed by $F$. avenaceum and $F$. solani, and $F$. verticillioides each ranging from 8 to $12 \%$ of the isolates. Other species such as $F$. fujikuroi and F. tricinctum, represented $5 \%$ to $7 \%$ of the total isolates.

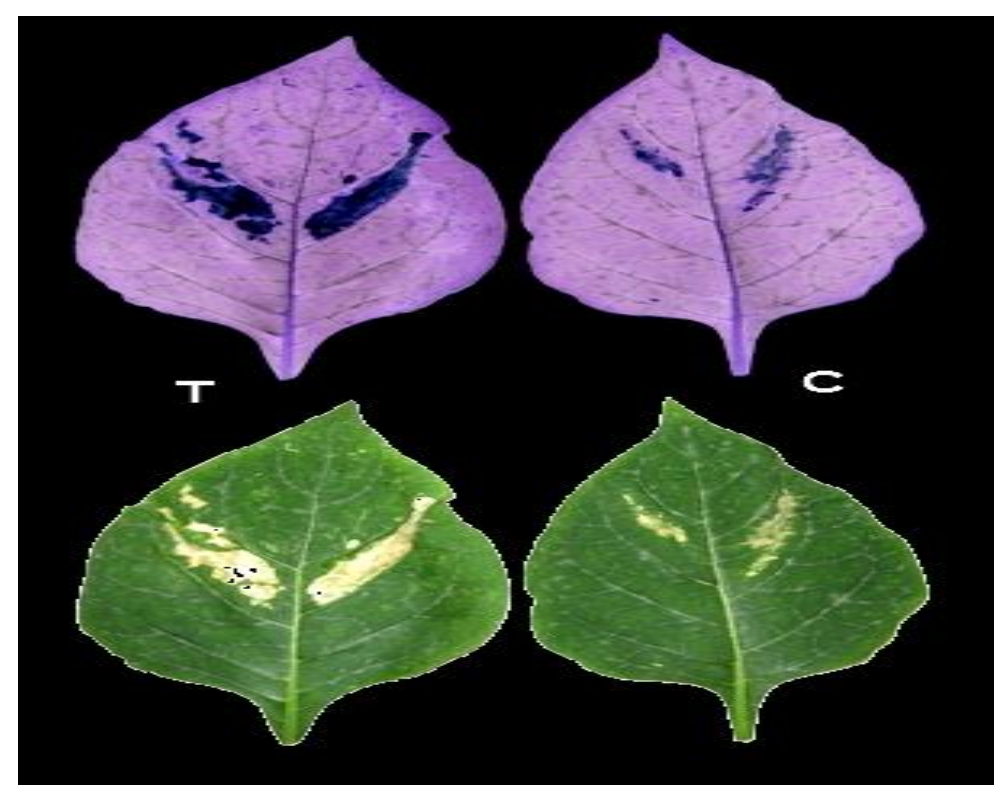

Fig 2 - Mycotoxin-induced lesion formation in Nicotiana benthamiana seedlings, the leaves infected with $F$. graminearum isolate 3 have abnormal colours (A). Leaves inoculated with water (C). The dark blue or lime colour indicates cell death.

\section{Chemotype analysis}

Results of chemical analyses relevant to the 103 isolates of Fusarium species are summarized in Table 1. ZEA, TRI and FUM toxins were produced by tested isolates of $F$. graminearum, $F$. solani, F. culmorum, F. equiseti, F. semitectum. F. verticillioides, $F$. fujikuroi, and $F$. poae. All isolates of $F$. acuminatum could produce ZEA at low level ranged from 87-271 $\mu \mathrm{g} / \mathrm{g}^{-1} . F$. verticillioides is the most important producer of fumonisin B1. Widely variations in fumonisin production were observed among isolates from the same plant host and geographic region. For 
example, isolate collected from Nigeria showed total fumonisin production values ranging from 615 (isolate 47) to $1074 \mu \mathrm{g} / \mathrm{g} \mathrm{-1}^{-1}$ (isolate 86) respectively. This is the first report of the production of fumonisins B1 by $F$. equiseti collected from corns and barely at level ranged from 244-407 $\mu \mathrm{g} / \mathrm{g}-1$ respectively. A group of 26 isolates was unable to produce detectable levels of mycotoxins screened in the current study. F. avenaceum, F. flocciferum, F. oxysporum, Fusarium spp. F. anthophilum, $F$. brevicatenulatum, $F$. ciliatum, and $F$. camptoceras isolates were found to be nontoxigenic. In some cases, no correlations between Nicotiana-based bioassay for mycotoxin screening and chemotype analysis, for instance, two isolates of $F$. annulatum, two isolates of $F$. chlamydosporum, and three isolates of $F$. verticillioides showed negative results by using Nicotiana-based bioassay, while showed positive by chemical analysis.

\section{Cluster analysis for toxin profiles}

A dendrogram based on UPGMA analysis using mycotoxins-producing ability data collected isolated from different grains imported into Saudi and Egypt. One hundred three isolates were assigned into two major clusters, the first cluster comprised $51.4 \%$ and the second cluster contains $49.6 \%$ of the tested isolates. Cluster analysis revealed the occurrence of six chemotype groups with similarities ranging from 85-98\% (Fig. 3). The first major cluster contains three different chemotype ZEA toxin producers $F$. heterosporium, $F$. tricinctum, $F$. proliferatum, and $F$. sporotrichioides, TRI toxin producers $F$. chlamydosporum, also, non-toxigenic isolates including $F$. avenaceum, F. flocciferum, F. oxysporum, Fusarium spp. F. anthophilum, F. brevicatenulatum, $F$. ciliatum, and $F$. camptoceras were grouped in the first major cluster together in a single well supported clade in this phylogeny. Whereas the ZEA, TRI, FUM toxin producers $(F$. graminearum, $F$. solani and $F$. culmorum) and FUM producing species $F$. verticillioides, $F$. fujikuroi, $F$. poae, and $F$. proliferatum were grouped within the second major cluster with similarity level ranged from 90 $89 \%$. Emphasizing the close evolutionary relatedness among them and agreeing with the type of mycotoxin that these species produce. The average similarities within a cluster were greater than the average similarities between the clusters. No clear-cut relationships between mycotoxinproducing ability and geographic origin of the isolates were evident.

\section{Species-specific PCR assays}

The occurrence of Zea, Tri and Fum genes, responsible for the production of three main mycotoxins in Fusarium spp., was studied. The specificity of the PCR reaction was tested on a diverse range of Fusarium species (25 species) commonly associated with different grains and seeds. Only DNA of $F$. graminearum and $F$. culmorum was amplified with ZEA2_dm_fA1/ZEA2_dm_rA1 and generated a 340 bp PCR product (Fig. 4). No fragment was produced from none ZEA producing species indicating that the described PCR system is specific for ZEA producing species. The specificity of the tri6 primer set TRI6_dm_fA2/ TRI6_dm_rA1 had been tested by the specific amplification of several isolates of $F$. graminearum, F. culmorum, $F$. solani and $F$. chlamydosporum, whereas no fragment was generated from the none-trichothecene producing Fusarium species such as $F$. heterosporium and $F$. tricinctum. None of the $F$. avenaceum isolates resulted in the amplification of the 526-bp tri6 DNA fragment. F. solani, F. verticillioides, $F$. proliferatum, $F$. poae, $F$. graminearum and $F$. culmorum species-specific PCR amplification was obtained for all tested isolates with FUM6_dm_fA2/ FUM6_dm_rA1 primer set (Table 1). No amplification was obtained from the other Fusarium species. The expected DNA fragment (672 bp) was amplified from FB1 producers (Fig. 5). No PCR product was amplified from the remaining isolates that did not produce FB1. The presence of Tri5 gene was revealed in 33 of 103 examined isolates $(34 \%)$, which indicates the potential ability to produce trichothecene mycotoxins by these fungi. while 25 isolates possessed three of the analyzed genes. The greatest number of genes responsible for the production of three mycotoxins was observed in $F$. graminearum, and $F$. equiseti while the smallest in $F$. avenaceum. 


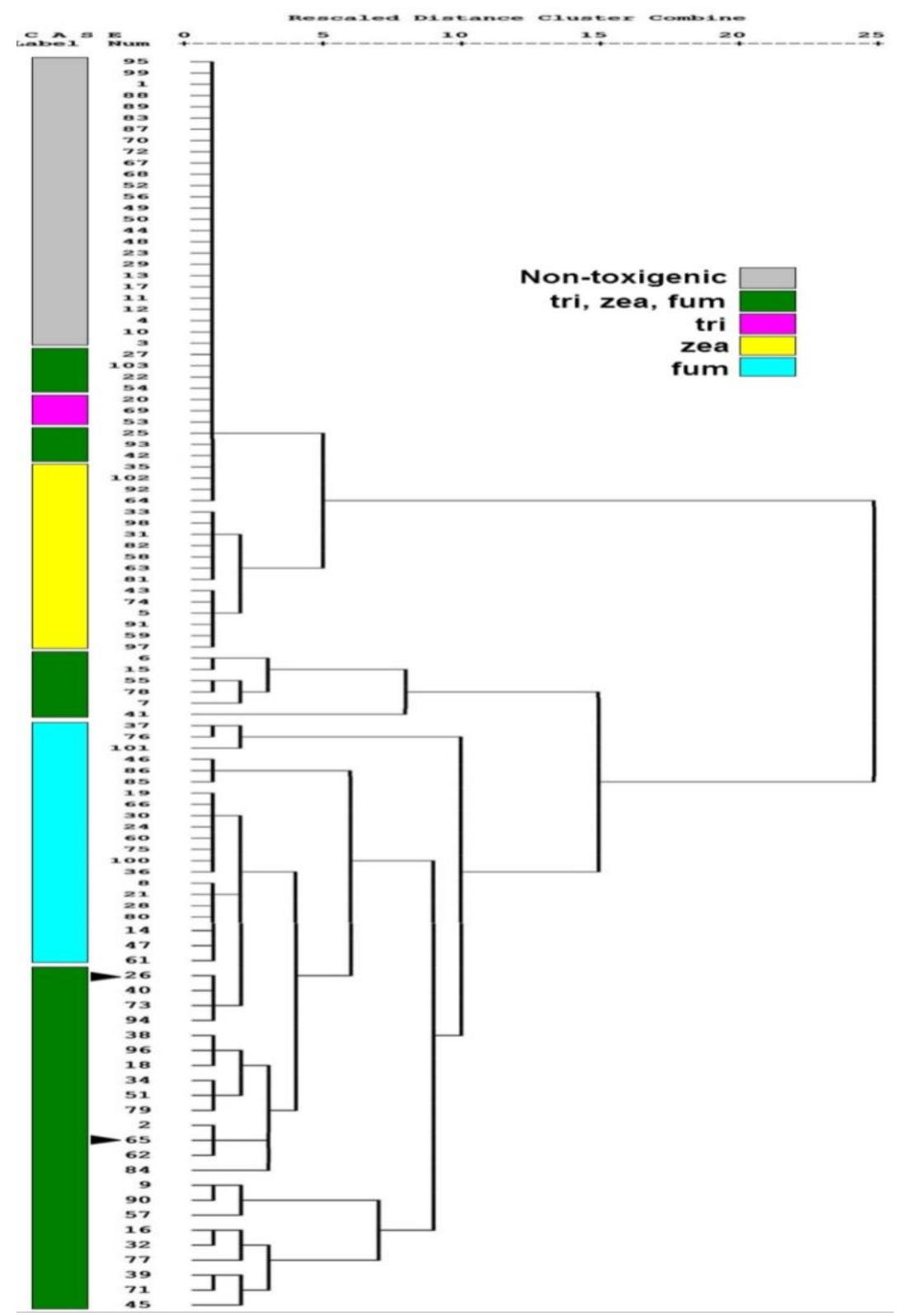

Fig 3 - Dendrogram based on average linkage cluster analysis of chemotype profiles (ZEA, TRI, FUM) obtained from 103 Fusarium isolates.

\section{LAMP-PCR}

The gaoA gene LAMP primer was used to detection of $F$. graminearum isolates, the assay was positive only for all $F$. graminearum isolates. There were minor cross reactions only with $F$. culmorum (isolate 73) other Fusarium isolates indicating good species specificity of the LAMPPCR for gaoA gene. No positive DNA products were observed when other toxigenic Fusarium ( $F$. sporotrichioides, $F$. avenaceum, and $F$. proliferatum) were used as templates (Fig. 6 A). CYP51C gene was used for identification and species-specific detection of different $F$. equiseti, the primers targeting unique regions of the CYP51C was confirmed by testing different Fusarium species. The results showed that the LAMP assay was highly specific for the detection of the appropriate species. The three tested $F$. equiseti isolates and Fusarium spp. (isolate 49) were produced positive amplification, whereas none of the primer sets amplified the template of any of the closely related species including, F. graminearum (tubes 13-15). F. solani (tubes 17-19), F. verticillioides (tubes 20,21 ), and $F$. heterosporium (tubes 22,23 ), thereby establishing the specificity of the LAMP assay for F. equiseti (Fig. 6 B). Amplification of DNA during the reaction was detected directly intube by colour transition of Calcein from orange to light yellow, visible to the naked eye, avoiding 
further post amplification analyses. Negative reaction did not show any colour variation and the typical electrophoresis pattern was absent (tubes 8, 16, 24). There was no difference between the LAMP results detected with the naked eye under a UV lamp or agarose gel electrophoresis (data not shown).

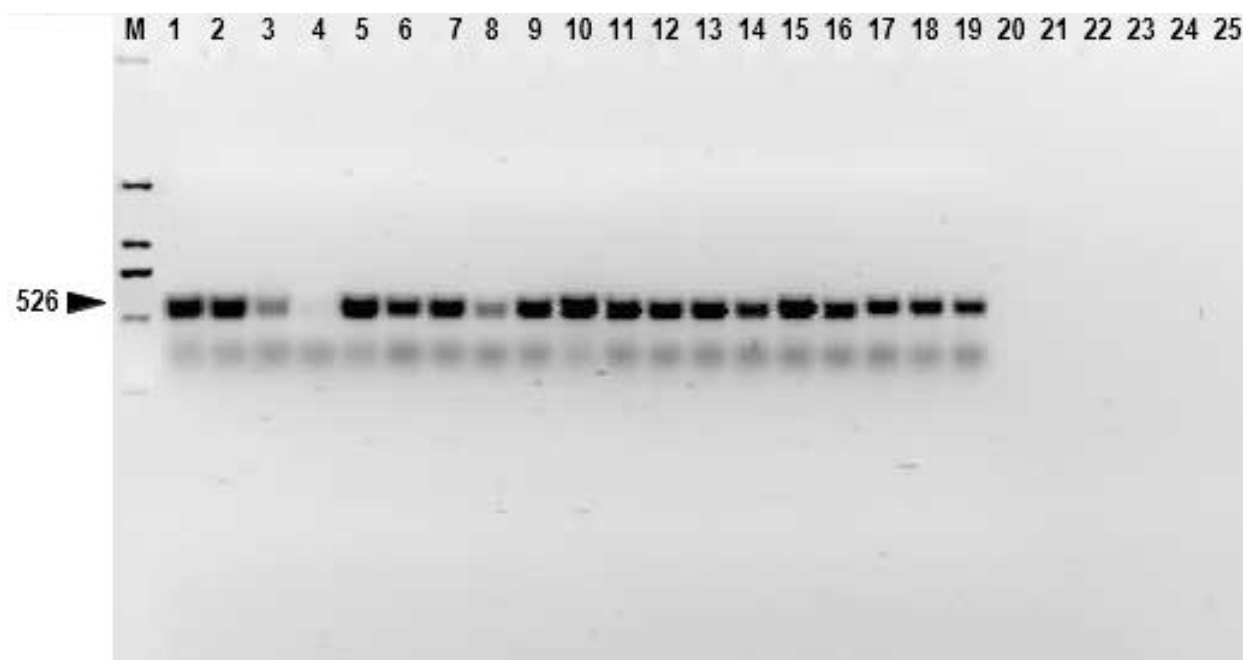

Fig 4 - Results of PCR assay with TRI6_dm_fA2/ TRI6_dm_rA1, trichothecene-specific primers (tri6) and genomic DNA extracted from Fusarium isolates. Lane M, 100 bp DNA ladder; lanes 1$12 ; F$. graminearum isolates, lanes 13-15; isolates of $F$. culmorum, lanes 16-17; F. fujikuroi isolates, lanes $18-19 ; F$. sporotrichioides isolates, lanes $20-21 ; F$. equiseti isolates, lanes; 22-23 $F$. tricinctum isolates, lanes $24-25 ; F$. poae isolates recovered from grain and seed samples. As size standard, 100 bp DNA ladder DL 2000 (TaKaRa, Japan) was used to determine the size of the products.

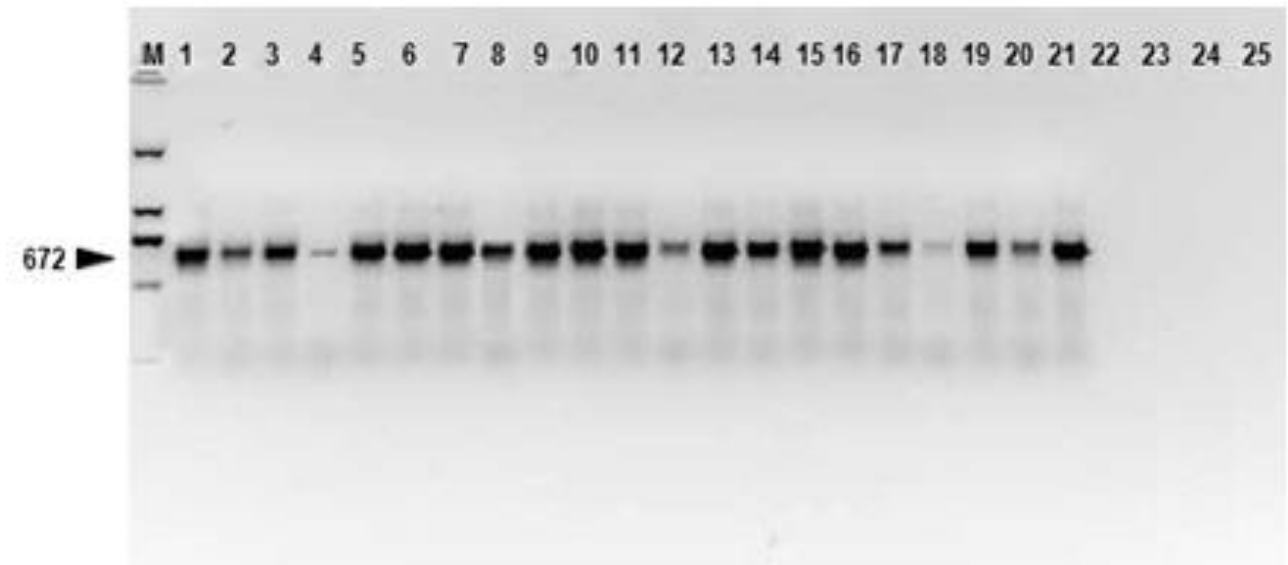

Fig 5 - Results of PCR assay with FUM6_dm_fA2/ FUM6_dm_rA1, fumonisin-specific primers (fum6) and genomic DNA extracted from Fusarium isolates. Lane M, 100 bp DNA ladder; lanes 18; F. verticillioides isolates; lanes 9-14; $F$. proliferatum isolates of $F$. solani, lanes 15-18; $F$. equiseti, isolates, lanes 19-20; lane 21, F. moniliforme isolates, lanes, 22-23; F. tricinctum isolates, lanes 24-25; $F$. avenaceum isolates recovered from grain and seed samples. As size standard, 100 bp DNA ladder DL 2000 (TaKaRa, Japan) was used to determine the size of the products. 


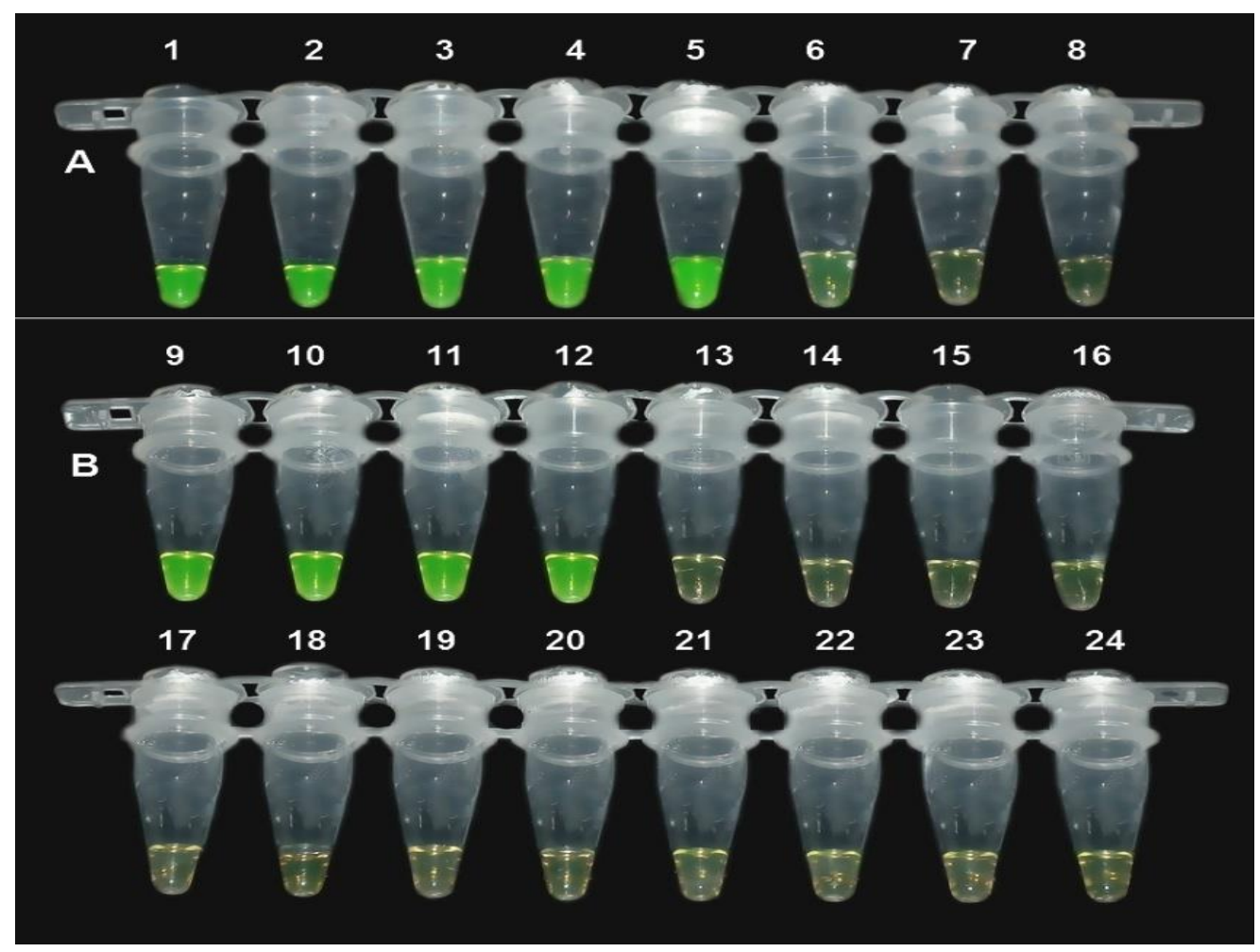

Fig 6 - The detection of loop mediated isothermal amplification (LAMP) products were visualized by fluorescent detection reagent and UV light. (A) LAMP for detection of $F$. graminearum using gaoA gene, $F$. graminearum (tubes 1-4), F. culmorum (tubes 5-6), F. sporotrichioides (Tube 7), $F$. avenaceum (tubes 20,21), and $F$. proliferatum (tubes 23,23). (B) LAMP detection of the CYP51C gene, F. equiseti (tubes 9-11), Fusarium spp. (tube 12). F. graminearum (tubes 13-15). F. solani (tubes 17-19), F. verticillioides (tubes 20, 21), and F. heterosporium (tubes 22, 23). Positive samples produce a green colour almost immediately (tubes 1, 2, 3, 5, 5, 9, 10, 11 and 12), while negatives remain light yellow. Tubes $8,16,24$ represent a negative control without target DNA.

\section{Discussion}

The genus Fusarium is calculated approximately to include at least 300 genealogically exclusive phylogenetic species, although less than half have been formally identified (Aoki et al. 2014). The current research aimed to combine bioassay, chemotype, qualitative and quantitative methods for detecting the major toxigenic Fusarium-associated mycotoxins (zearelanone, trichothecenes and fumonisins B1). The tested fungi were isolated from imported grain and seeds imported into Egypt and Saudi Arabia. The analysis was conducted using 103 isolates of Fusarium belonging to 25 species. $F$. graminearum, $F$. culmorum, $F$. poae, and $F$. sporotrichioides are common in grain and are causative agents of Fusarium head blight disease (FHB), which causes great yield loss worldwide (Leslie \& Summerell 2006). F. verticillioides was the most widespread Fusarium species found on barley rootlets could be correlated with fumonisin B1 contamination (Cavaglieri et al. 2009). It is necessary to redefine the role of bioassay for the field diagnosis of mycotoxicoses, as tests on biological systems designed primarily to confirm the presence of mycotoxins (Panigra 1993, Lachaud et al. 2011). In the present study 57\% of the isolates showed the ability to produce three different mycotoxins by using Nicotiana-based bioassay. A number of fungal species secrete toxins to kill host cells and promote pathogen growth. The host-selective mycotoxin fumonisin B1 (FB1) is produced by the pathogen. It has been shown that the toxin induces programmed cell death (PCD) in animal and plant cells (Gilchrist et al. 1998). FB1-induced cell death was accompanied with disruption of vacuolar membrane tracked by lesion formation (Kuroyanagi et al. 2005). The higher FB1 dose leads to root growth inhibition and hypocotyl expansion on $N$. benthamiana seedlings (Brandwagt et al. 2001). ZEA, TRI and FUM toxins were 
produced by tested isolates of $F$. graminearum, F. solani, $F$. culmorum, F. equiseti, F. semitectum, $F$. verticillioides, $F$. fujikuroi, and $F$. poae. Our results found that $100 \%$ of isolates of $F$. graminearum infested cereals are toxigenic. ZEA is produced by different Fusarium species, such as the most important fungal pathogens of maize and wheat, i.e. F. graminearum F. culmorum and $F$. equiseti. The main toxins produced by $F$. graminearum are deoxynivalenol (DON) and zearalenone (ZEN) (Bottalico \& Perrone et al. 2002). With regard to ZEA and type B trichothecene production, $F$. graminearum, $F$. culmorum and $F$. cerealis are very closely related to one another, both morphologically and chemotaxonomically (Bottalico \& Perrone 2002, Nelson et al. 1983). The production of DON by $F$. acuminatum has been previously reported (Marín et al. 2012). In the present study all isolates of $F$. acuminatum could produce ZEA at low level ranged from 87-271 $\mu \mathrm{g} /{ }^{\mathrm{g}-1}$. We recommended that this species should not be considered a DON non-producing species, although more isolates and further studies are needed to prove this. The production of fumonisins B1 from $F$. equiseti isolates was reported for the first time. Cluster analysis revealed the occurrence of six groups with similarities ranging from 85-98\%. There was no straight relationship between type of mycotoxins and their collected crop or geographic origins. Recently, the probable use of sequence analysis and biosynthetic gene-derived molecular markers was applied to taxonomic and chemotype studies, utilizing both toxic (fumonisins, trichothecenes, zearalenone, fusaric acid, fusarins, enniatins and beauvericin) and nontoxic (bikaverin) metabolites produced by Fusarium fungi was described (Stępień et al. 2014). There have been reports of collective detection of trichothecene producing Fusarium species with a PCR-based assay based on trichothecene biosynthetic genes (Aoki 2014, Dawidziuk 2014, Stępień et al. 2014) as well as for fumonisin producing Fusarium based on genes in the fumonisin biosynthetic cluster (LópezErrasquín et al. 2007). Very recently the gene cluster of ZEA biosynthesis has been identified in $F$. graminearum which containing zea2 gene (Dawidziuk et al. 2014). Three chemotypes were identified by chemical analysis and confirmed by PCR and LAMP-PCR. PCR assays of Zea2, Tri6, and Fum B1 genes were used to predict whether these isolates could produce zearalenone (ZEA), deoxynivalenol (DON), and fumonisins (FUM) respectively. The greatest number of genes responsible for the production of three mycotoxins was observed in $F$. graminearum, and $F$. equiseti while the smallest in $F$. avenaceum. PCR amplification of FUM6 gene can be a useful tool for the fast detection of fumonisin B1-producing $F$. verticillioides and $F$. proliferatum isolates. The toxigenic Fusarium isolates were detected trichothecenes-, zearalenone-, fumonisins-producing Fusarium with the sensitivity ranged from (94-100\%) and ranged from specificity (88-95\%) (Dawidziuk et al. 2014). There was no correlation between the country of origin and the presence of the marker fragment. PCR assays results were matched quite well with the chemistry for almost of isolates that were shown to produce trichothecenes. PCR assays give structural, rather than functional information, thus reflecting the presence of a sequence or a gene but not necessarily its expression. Numerous developed isothermal DNA-based amplification techniques for food-borne bacterial and fungal contaminants as an alternative to PCR-based assays was reviewed by Niessen (2013). A few number of studies for detection of toxigenic Fusarium using LAMP assays showed that the approach was easier and faster to perform than common PCR assays, as well as being more specific (Niessen \& Vogel 2010, Abd-Elsalam 2011, Niessen 2012, Almoammar 2013, Lu et al. 2015b). In this study, we used LAMP primer sets designed from gaoA gene and CYP51C gene for detection of $F$. graminearum, $F$. equiseti isolates, respectively. Our experimental results suggest that LAMP can detect $F$. equiseti and $F$. graminearum faster and with higher sensitivity than the traditional diagnostic method. DNA from more slightly related Fusarium spp. except $F$. culmorum was not amplified with the primer set used even if incubation was extended to more than 80 min. Results showed that the LAMP assay for $F$. graminearum is highly specific for that species but also picks up all the genetic lineages of it which were recently erected as species, e.g. F. graminearum sensu lato (O'Donnell et al. 2004). These findings are in conformity with earlier studies that the specificity of LAMP method in identification of toxigenic Fusaria such as $F$. graminearum and $F$. equiseti is extremely high (Niessen \& Vogel 2010, Dawidziuk et al. 2014). CYP51C is conserved and is common in $F$. equiseti and $F$. graminearum; therefore, the CYP51C gene sequence is a better 
for detecting $F$. equiseti and $F$. graminearum than rDNA-ITS or the $\beta$-tubulin gene sequence (Deng 2007, Niessen \& Vogel et al. 2010). The method uses six primers (FIP, BIP, F3, B3, LF and LB) that recognize eight regions of DNA for the target pathogen and it amplifies DNA within sixty minutes at $65^{\circ} \mathrm{C}$ in a thermblock, water-bath and thermal cycler, to validate the efficiency and specificity (Notomi 2000, Mori et al. 2004). In addition, great amounts of white magnesium pyrophosphate precipitate were generated in amplified samples, which assisted the identification of $F$. equiseti and $F$. graminearum based on naked-eye examination. Therefore, LAMP method is a widely applied as a diagnostic and detection tool for the most important plant pathogenic fungi (Niessen \& Vogel 2010, Abd-Elsalam 2011, Niessen 2012, Almoammar 2013, Lu et al. 2015b).

In conclusion, ZEA, TRI and FUM toxins were produced by tested isolates of $F$. graminearum, $F$. solani, F. culmorum, $F$. equiseti, F. semitectum. F. verticillioides, $F$. fujikuroi, and $F$. poae. The data from the Nicotiana-based assay were robust and predictable, and well-correlated with chemical analysis of mycotoxins. The greatest number of genes responsible for the production of three major mycotoxins was detected in $F$. graminearum, and $F$. equiseti while the smallest in $F$. avenaceum. The LAMP assay could serve as a simple and quick technique with potential application for on-site disease detection and field surveys. A diagnostic method which is rapid, accurate, and simple could really help to control of toxigenic fungi and reduction of mycotoxins produced by Fusarium species in various agricultural commodities.

\section{Acknowledgments}

Thanks are due to the Unit of Excellence in NanoMolecular Plant Pathology Research, Agricultural Research Center (ARC), Egypt. Current work was supported by the Science and Technology Development Fund (STDF), Egypt (STDF-STF program to Kamel Abd-Elsalam) [grant no. 5442].

\section{References}

Abd-Elsalam KA, Bahkali AH, Moslem MA, Amin O, Niessen L 2011 - An optimized protocol for DNA extraction from wheat seeds and loop-mediated isothermal amplification (LAMP) to detect Fusarium graminearum contamination of wheat grain. International Journal of Molecular Science12, 3459-3472.

Almasi MA, Moradi A, Ojaghkandi MA, Aghaei S. 2013 - Development and application of loopmediated isothermal amplification assay for rapid detection of Fusarium oxysporum f. sp. lycopersici. Journal of Plant Pathology and Microbiology 4, 2.

Almoammar H, Bahkali AH, Abd-Elsalam KA. 2013 - One-hour loop-mediated isothermal amplification assay for detection quarantinable toxigenic Fusarium garmanirum. African Journal of Microbiology Research 7, 1179-1183.

Antonissen G, Martel A, Pasmans F, Ducatelle R, Verbrugghe E, Vandenbroucke V, et al. 2014 The impact of Fusarium mycotoxins on human and animal host susceptibility to infectious diseases. Toxins 6, 430-452.

Aoki T, O’Donnell K, Geiser DM. 2014 - Systematics of key phytopathogenic Fusarium species: current status and future challenges. Journal of General Plant Pathology 80, 189-201.

Baird R, Abbas HK, Windham G, Williams P, Baird S, Ma P, Kelley R, Hawkins L. et al. 2008 Identification of select fumonisin forming Fusarium species using PCR applications of the polyketide synthase gene and its relationship to fumonisin production in vitro. International Journal Molecular Science 9, 554-570.

Bottalico A, Perrone G. 2002 - Toxigenic Fusarium species and mycotoxins associated with head blight in small-grain cereals in Europe. European Journal of Plant Pathology 108, 611-624.

Brandwagt BF, Kneppers TJA, Van der Weerden GM, Nijkamp HJJ, Hille J. 2001 - Most AAL toxin-sensitive Nicotiana species are resistant to the tomato fungal pathogen Alternaria alternata f. sp. lycopersici. Molecular Plant-Microbe Interactions 14, 460-470. 
Cavaglieri LR, Keller KM, Pereyra CM, González Pereyra ML, Alonso VA, Rojo FG, Dalcero AM, Rosa CAR, 2009 - Fungi and natural incidence of selected mycotoxins in barley rootlets. Journal of Stored Products Research 45, 147-150.

Dai TT, Lu CC, Lu J, Dong S, Ye W, Wang Y, Zheng X. 2012 - Development of a loop-mediated isothermal amplification assay for detection of Phytophthora sojae. FEMS Microbiology Letters 334, 27-34.

Dawidziuk A, Koczyk G, Popiel D, Kaczmarek J, Busko M, 2014 - Molecular diagnostics on the toxigenic potential of Fusarium spp. plant pathogens. Journal of Applied Microbiology 116, 1607-1620.

Deng J. 2007 - Structural, functional and evolutionary analyses of the rice blast fungal genome. North Carolina State University, North Carolina.

Ferrara M, Perrone G, Gallo A., Epifani F, Visconti A, Susca A. 2015 - Development of loopmediated isothermal amplification (LAMP) assay for the rapid detection of Penicillium nordicum in dry-cured meat products. International Journal of Food Microbiology, DOI: 10.1016/j.ijfoodmicro.2015.02.021.

Gilchrist DG. 1998 - Programmed cell death in plant disease: the purpose and promise of cellular suicide. Annual Review of Phytopathology 36, 393-414.

Gong L, Jiang Y, Chen F. 2014 - Molecular strategies for detection and quantification of mycotoxin-producing Fusarium species: a review. Journal of Science of Food Agriculture DOI: $10.1002 /$ jsfa.6935.

Hammond TM, Tsitsigiannis DI, Keller NP. 2007 - Development of an Arabidopsis thaliana-based bioassay for investigating seed colonization by mycotoxigenic Aspergillus species. Plant Pathology 56, 848-854.

Hilton AJ, Jenkinson P, Hollins TW, Parry DW (1999). Relationship between cultivar height and severity of Fusarium ear blight in wheat. Plant Pathology 48, 202-208.

Huffman J, Gerber R, Liangcheng DU. 2010 - Recent advancements in the biosynthetic mechanisms for polyketide-derived mycotoxins. Biopolymers 93, 764-776.

Jeon YA, Yu SH, Lee YY, Park HJ, Lee S, Sung JS, et al. 2013 - Incidence, molecular characteristics and pathogenicity of Gibberella fujikuroi species complex associated with rice seeds from Asian countries. Mycobiology 41, 225-233.

Jia Y, Wamishe YA, Zhou B. 2014 An expedited method for isolation of DNA for PCR from Magnaporthe oryzae stored on filter paper. The Crop Journal 2: 267-271.

Kuroyanagi M, Yamada K, Hatsugai N, Kondo M, Nishimura M, Hara-Nishimura I 2005 Vacuolar processing enzyme is essential for mycotoxin-induced cell death in Arabidopsis thaliana. Journal of Biological Chemistry 280, 32914-32920.

Kushiro M. 2013 - Analysis of major Fusarium toxins and their retention during processing. Mycotoxins 63, 117-131.

Lachaud C, Da Silva D, Amelot N, Be'ziat C, Brie`re C, Cotelle V, Graziana A, Grat S, Mazars C, Thuleau P. 2011 - Dihydrosphingosine-induced programmed cell death in tobacco BY-2 cells is independent of $\mathrm{H}_{2} \mathrm{O}_{2}$ production. Mol Plant 4, 310-318.

Law JWF, Ab Mutalib NS, Chan KG, Lee LH. 2014 - Rapid methods for the detection of foodborne bacterial pathogens: principles, applications, advantages and limitations. Frontiers in Microbiology 5, 770. DOI:10.3389/fmicb.2014.00770.

Leslie JF, Summerell BA. 2006 -The Fusarium Laboratory Manual. Blackwell Publishing, Ames, IA.

Li B, Du J, Lan C, Liu P, Weng Q, Chen Q. 2013 - Development of a loop-mediated isothermal amplification assay for rapid and sensitive detection of Fusarium oxysporum f. sp. cubense race 4. European Journal of Plant Pathology 135, 903-911.

López-Errasquín E, Vázquez, C, Jiménez M, González-Jaén MT. 2007 - Real-Time RT-PCR assay to quantify the expression of fum 1 and fum 19 genes from the Fumonisin-producing Fusarium verticillioides. Journal of Microbiological Methods 68, 312-317. 
Lu C, Dai T, Zhang H, Wang Y, Zheng X. 2015a - Development of a loop mediated isothermal amplification assay to detect Fusarium oxysporum. Journal of Phytopathology 163, 63-66.

Lu C, Zhang H, Wang Y, Zheng X. 2015b - Rapid diagnosis of Fusarium root rot in soybean caused by Fusarium equiseti or Fusarium graminearum using loop-mediated isothermal amplification (LAMP) assays. Australasian Plant Pathol. DOI: 10.1007/s13313-015-0361-8.

Marín P, Moretti A, Ritieni A, Jurado M, Vázquez C, M. Teresa González-Jaén. 2012 Phylogenetic analyses and toxigenic profiles of Fusarium equiseti and Fusarium acuminatum isolated from cereals from Southern Europe. Food Microbiology 31, 229-237.

Mori Y, Kitao M, Tomita N, Notomi T. 2004 - Real-time turbidimetry of LAMP reaction for quantifying template DNA. Journal of Biochemistry Biophysics Methodology 59, 145-157.

Nelson PE, Toussoun TA, Marasas WFO. 1983 - Fusarium species: an illustrated manual for identification. Pennsylvania State University Press, University Park, PA, USA.

Niessen L, Gräfenhan T, Vogel RF. 2012 - ATP citrate lyase 1 (acl1) gene-based loop-mediated amplification assay for the detection of the Fusarium tricinctum species complex in pure cultures and in cereal samples. International Journal of Food Microbiology 158, 171-185.

Niessen L, Vogel RF 2010 - Detection of Fusarium graminearum DNA using a loop-mediated isothermal amplification (LAMP) assay. International Journal of Food Microbiology 140, 183-191.

Niessen, L, Luo J, Denschlag, C, Vogel RF. 2013 - The application of loop-mediated isothermal amplification (LAMP) in food testing for bacterial pathogens and fungal contaminants. Food Microbiology 36, 191-206.

Notomi T, Hiroto O, Harumi M, Toshihiro Y, Watanabe K, Nobuyuki A, Hase T. 2000 - Loopmediated isothermal amplification of DNA. Nucleic Acids Research 28, 63.

O'Donnell K, Ward TJ, Geiser DM, Kistler HC, Aoki T. 2004 - Genealogical concordance between the mating type locus and seven other nuclear genes supports formal recognition of nine phylogenetically distinct species within the Fusarium graminearum clade. Fungal Genetics and Biology 41, 600-623.

Panigra S. 1993 Bioassay of mycotoxins using terrestrial and aquatic, animal and plant species. Food Chem. Toxic. 31, 767-790.

Peng J, Zhan Y, Zeng F, Long H, Pei Y, Guo J. 2013 - Development of a real-time fluorescence loop-mediated isothermal amplification assay for rapid and quantitative detection of Fusarium oxysporum f.sp. niveum in soil. FEMS Microbiol Letter 349, 127-134.

Rivas-San Vicente M., Larios-Zarate G., Plasencia J. 2013 - Disruption of sphingolipid biosynthesis in Nicotiana benthamiana activates salicylic acid-dependent responses and compromises resistance to Alternaria alternata f. sp. lycopersici. Planta 237, 121-136.

Stępień L. 2014 - The use of Fusarium secondary metabolite biosynthetic genes in chemotypic and phylogenetic studies. Critical Review of Microbiology 40, 176-185.

Storari M, von Rohr R, Pertot I, Gessler C, Broggini GAL. 2013 - Identification of ochratoxin A producing Aspergillus carbonarius and A. niger clade isolated from grapes using the loopmediated isothermal amplification (LAMP) reaction. Journal of Applied Microbiology 114, 1193-1200.

Urban M, Daniels S, Mott E, Hammond-Kosack K, 2002 - Arabidopsis is susceptible to the cereal ear blight fungal pathogens Fusarium graminearum and Fusarium culmorum. The Plant Journal 32, 961-973.

Wang J, Wang J, Li X, Dong S, Zhang Z, Zheng X. 2013 Rapid molecular detection of Fusarium oxysporum by PCR. Acta Phytopathol Sinica 43, 318-322.

Wolny-Koładka KA. 2015 - The prevalence of selected genes involved in the bio synthesis of trichothecenes assessed with the specific PCR tests in Fusarium spp. isolated from cereals in southern Poland. Journal of Environmental Science and Health, Part B 50, 361-367. 
Zhang WW, Jin, Y, Ye ZM, Wang SY, Solfrizzo M, Xu X, Pei XF. 2014 - Development of loopmediated isothermal amplification assay for rapid screening of fungal contamination in pepper and paprika powder. Quality Assurance and Safety of Crops \& Foods. DOI: 10.3920/QAS2013.0266 